\title{
Centaurs at the Symposium: Two Types of Hybridity in Lucian
}

\author{
MEGAN HANCOCK \\ University of Tasmania
}

\begin{abstract}
Introduction
Hybridity in the works of Lucian takes on many forms; his creation of the seriocomic genre is itself defined as a hybrid (Luc. Prom. Es. 5), and he is himself a hybrid of Syrian and Greek cultures. However, for the following discussion, the focus is upon Lucian's presentation of the hybrid philosopher-sophist. With reference to two particular dialogues, Zeuxis and the Symposium, ${ }^{1}$ it becomes clear that there are two types of hybridity in Lucian's works. The first of these presents the hybrid form as something worthy of praise, provided the melding of two disparate forms is done in a way that is seamless and aesthetically pleasing (Möllendorff 2006). The successful hybrid is evident in the Zeuxis, wherein Lucian describes a painting of a family of centaurs. Yet significantly this stands in direct contrast to the presentation of the corrupted hybrid, featured in Lucian's Symposium. Here, the philosopher-sophist is shown to be a corrupted hybrid, responsible for the corruption of contemporary philosophy.

Lucian thus presents two distinct incarnations of the hybrid. In the first instance, the hybrid centaur is portrayed in a positive light, representing a source of wisdom reminiscent of Chiron (Fantham 2003). In contrast, the supposedly learned philosopher-sophist comes to embody the traditional characteristics of the hybrid: uncivilised, immoral and corrupted.
\end{abstract}

${ }^{1}$ Translations of Lucian's Symposium and Zeuxis have been taken and adapted where necessary from A.M. Harmon 1913 and Kilburn 1959. 


\section{The Hybrid}

Scholarship upon the hybrid as a metaphor and rhetorical tool has, in recent years, sought to prescribe a strict definition of the hybrid. The hybrid, as Kapchan and Strong state, can refer to "not only animals and plants... but people, cultures, traditions, and languages as well" (Kapchan, Strong 1990, 240). Significantly, the hybrid is "effected whenever two or more historically separate realms come together in any degree that challenges their socially constructed autonomy" (Kapchan 1996,6). The challenge to a "socially constructed autonomy" is a core feature of formulating a hybrid. Stross notes that the boundaries between the two "parents" 2 of the hybrid must be separate enough in order to qualify as a true hybrid (Stross 1999, 258). He gives the example of two breeds of floppy-eared rabbits, arguing that despite the difference in breeds, the progeny of the two animals is insufficiently different to be considered a true hybrid. However, they must also be significantly similar, noting the impracticality of a hybrid consisting of an elephant and a canary (Stross 1999, 259), and moreover this infeasibility of what he deems "biological" hybridity, must be applied in a similar manner to notions of "cultural" hybridity, that is, the combination of disparate "discourse genres, languages and other cultural phenomena" (Stross 1999, 257). The formulation of the hybrid, therefore, must follow something of a set of rules; the hybrid must successfully challenge the "socially constructed autonomy" through a combination of appropriately "separate realms."

It is in this definition of hybridity that the following discussion is framed, as it allows for the appropriately separate realms of philosophy and sophistry to enter the broader conversation. In what follows, I will consider this preoccupation with hybridity that pervades the Second Sophistic, and then assess its broader function in the works of Lucian.

The predominant 'function' of the hybrid thus lies in the context of using the hybrid creature as a metaphor for the philosopher-sophist, implying that a form of corruption or impurity has taken place in the subject in question. This function of hybridity is evident in Lucian himself, as in Lucian's Fugitivi, the sophist is not unlike the centaur: a hybrid creature, incapable of being wholly dedicated to philosophy or to ignorance, wandering in the interspace between an impersonator and a philosopher (Luc. Fug. 10). This function of hybridity in relation to sophistic philosophical discourse becomes a pervasive one for other authors in the early

\footnotetext{
${ }^{2}$ On the subject of hybrid parents, Stross does acknowledge that the cultural hybrid, in contrast to the biological hybrid, may consist of two parents, due to the means by which hybridity occurs as processes of "diffusion, invention, learning, cultural assimilation and construction" (Stross 1999, 264).
} 
Roman empire. As Bowersock notes, the sophists of the Roman Empire played a core role in the creation of a cohesive culture, spreading sophistic teachings through the power of rhetoric (Bowersock 1969). It is from this most basic definition of sophistic practice that it is possible to view the period as embracing a form of cultural hybridity. These 'Greek Sophists' stretch between Roman, Greek and Eastern identities, elite and non-elite audiences, and traditional and modern genres, allowing the period to become a Protean one in its own right, "beguiling but endlessly elusive" (Whitmarsh 2005, 19). König notes the literary hybridity that pervades the Second Sophistic, and encourages a view of the literary environment as fluid and varied, exploring notions of authorship (or lack thereof) throughout the works and their role within the broader conception among the educated elite. At the most basic level, the extant texts of this period are inherently a product of elite society, with authors frequently trumpeting their own education and intellect, often through a concerted effort to better their reputation, which comes to override philosophical teaching. König highlights these elite pretenses in the context of the ancient novel, noting specifically that the elitism that pervades these texts is directly presented as Greek superiority, idealising Classical Greece in direct opposition to the comparatively foreign culture of the Roman Empire (König 2009, 19-21). These tensions between the elite and non-elite and the Greek and the foreign are, for the following discussion, useful illustrations of the hybridity of the era, and thus it is not surprising that such a tension is portrayed by Imperial authors as producing corruptions of form, particularly that of the philosopher-sophist hybrid.

Philostratus' Lives of the Sophists, depicts the 'philosopher-sophist' to be distinguished from the real sophist; they are not explicitly classed as a hybrid of form, however are certainly ranked in a different class as the proper sophists (V.S. 1,484). This insinuation of hybridity is also a feature of the Life of Apollonius; Billault notes that despite Apollonius' positioning of rhetoric as lesser than philosophy, Philostratus nonetheless portrays the 'divine man' as a hybrid figure, an intermediary not only between divinity and humanity, but also between sophistry and philosophy (Billault 1993, 274; Billault 1993, 228; 234).

In these two instances, the hybrid philosopher-sophist hardly suggests any element of corruption, however the apparent philosopher-sophist himself, ${ }^{3}$ Dio Chrysostom, certainly embraces such a notion. In Dio's Fourth Discourse on Kingship, he relates the meeting of Alexander the Great with the Cynic philosopher Diogenes of Sinope. Following a lengthy discussion regarding Alexander's aspirations to be a true king, Diogenes outlines the three primary types of 'lives'

${ }^{3}$ Philostratus includes Dio of Prusa as one of the aforementioned philosophers with the reputation of being a sophist, but not a sophist proper (V.S. 1,485). 
that mankind often lead (Dio Chrys. 4,83). Of importance for the following discussion is the third 'life', 'spirit', or 'character' (Bíos; Moles, 1983, 258), which

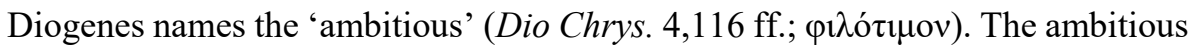
spirit, states Diogenes, is concerned first and foremost with its own reputation. Those who are imbued with this spirit, he states, should be likened to Ixion, the hero who is said to be the father of Kentauros (Apoll. E. 1,20), the turning of the wheel acting as a metaphor for the ambitious spirit's proclivity towards flattery (Dio Chrys. 4,123). The likeness to Ixion goes further, as the ambitious spirit is said to be completely charmed and blindsided by Delusion, not unlike Ixion's own inability to perceive that he had chosen the reputation of believing he had slept with Hera over being able to perceive the reality. This act, states Diogenes, of being charmed by Delusion, can produce "nothing useful or serviceable... but only strange irrational creations that resemble the centaurs" (Dio Chrys. 4,131). These strange irrational creations, he states, are now not the actual hybrid beasts but the "political acts of certain demagogues and the treatises of sophists" (Dio Chrys. 4,131).

It is hardly a stretch to understand Dio's oration to be a direct critique of the hybrid and unnatural manner of the philosopher-sophists. ${ }^{4}$ Consequently, it is clear that hybridity, in the Second Sophistic more broadly, plays a particular role in acting as a metaphor for a corrupted or unnatural construct. With this in mind, it is useful to turn directly to the works of Lucian, as it is here that the metaphor of the hybrid becomes more elaborate.

\section{Lucianic Hybrids}

The hybrid appears frequently throughout Lucian's works. As alluded to above, the hybrid makes an appearance in Lucian's discussion of his own creations, as the combination of dialogue and comedy, he admits, is not unlike the Egyptian camel - half black, half white, and wholly monstrous in its hybrid form (Prom. Es. 4-5). ${ }^{5}$ In mixing the two literary genres, he states, he has diminished the beauty of each, becoming the epitome of the disharmonious Lucianic hybrid. ${ }^{6}$ Yet the hybrid centaur comes to embrace a number of different forms throughout Lucian's works. In his Gallus, the hybrid animal appears not as a centaur, but as a speaking

\footnotetext{
${ }^{4}$ As Moles notes, instances of what he terms "sophist-bashing" appear quite frequently throughout the text (Dio Chrys. 4,27-39). (Moles 1983, 271).

${ }^{5}$ For a detailed analysis of Lucian's use and manipulation of the Promethean tradition, and its relationship to the hybrid genre, see ní Mheallaigh 2014, 2-8.

${ }^{6}$ The definition and examination of the ideal Lucianic hybrid is discussed is greater detail below.
} 
rooster and as Menippus adopts wings so as to fly to the heavens in the Icaromennipus, he becomes a hybrid creature, capable of inhabiting both the human world and the heavens. The hybrid animal too makes an appearance in his Verae Historiae, with the main character encountering all sorts of hybrid creatures throughout his journey across the skies (V.H. 1,11ff.). For the following discussion however, the focus is upon the explicit use of the hybrid as a metaphor for corrupted philosophers. As noted above, the depiction of the philosopher-sophist as a centaur in Lucian's Fugitivi (Fug. 10) is constructed as an attack against the Cynic doctrine. They appear to be philosophers in "deportment, glance and gait," (Fug. 4), yet in truth they are ignorant and insulting to the name of philosophy. The hybrid philosopher-sophist features similarly in the Peregrinus. Here, Lucian utilises the metaphor of the hybrid to critique the Cynic-turned-Christian Peregrinus, who is not discredited for his philosophical doctrine, but the manner in which he conducts himself - concerned only with his reputation (König 2009, 247).

The hybrid, in Lucian, therefore, takes on a very malleable and important role, coming to act as a serviceable literary tool for satire. However, it is in particular the depiction of the hybrid centaur that is the focus for this discussion, as not only does it represent the epitome of a corrupted mixture, but it also comes to represent the pinnacle of hybrid success.

\section{Centaurs}

In Lucian's Symposium, or the Lapiths, the hybrid philosopher-sophists are likened to centaurs, and the dialogue as a whole is modelled upon the mythological centauromachy. Lucian transforms the quarrelsome nature of the philosophers into a very literal brawling match, to the extent that 'you would have said they were Lapiths and Centaurs' (Luc. Symp. 45). This depiction of the philosopher as emulating the violent centaur is curious when taken in consideration of the actual centaurs, found in his Zeuxis. Here, the hybrid animal is shown in the context of an idyllic and civilised family unit, a stark contrast to their philosopher counterparts.

In Lucian's text, the family of centaurs becomes humanised, with the emphasis being upon the civilised aspects of the inherently hybrid creature. However this is an unusual depiction of the hybrid creature, which is distinct from the violent, savage centaur that is dominant throughout classical literature, ${ }^{7}$ as is evident in Book 12 of Ovid's Metamorphoses. Here, Ovid offers perhaps the most wellknown re-telling of the famous battle between the Centaurs and the Lapiths. The

${ }^{7}$ For a detailed discussion of the wild nature of the centaur, see Bremmer, 2012. 
marriage of Pirithous and Hippodame calls for celebration, leading the newlyweds to invite the race of centaurs as guests. The centaurs, having grown 'heated with wine or lust or both of them together' (Ov. Met. 12,220-23) reveal their wild nature, seizing the female guests and thus triggering the battle. Nestor, in his guise as narrator of the battle, almost instantly reminds the reader that the violence takes place during a dinner party: "All utensils meant for feasting were used for war and murder" (Ov. Met. 12.243-244), which as will be shown, becomes crucial for the comparison of this narrative with that depicted in Lucian's Symposium. Ovid's Metamorphoses also depicts skulls being crushed by tableware, eyes being pierced, boulders being thrown, the bodies of Lapiths and Centaurs alike being maimed and mutilated (Ov. Met. 12, 221ff). This violent and evocative language is replicated in Lucian's account, with the philosophers of the Symposium acting as if engaged in a pub brawl. ${ }^{8}$

However in addition to this extreme violence, there exists a depiction of the race of centaurs that more closely resembles that which is found in Lucian's Zeuxis. As DeBrohun discusses, in the context of the Metamorphoses, the violent episode is interrupted by a short description of a centaur couple, Cyllarus and Hylonome, who, upon entering the battle, are almost immediately struck down. Their description is dominated by an emphasis upon the beauty of the two centaurs' forms; the hybrid animal is a harmonious combination of horse and man, and he exists as a perfect example of such a beast (Debrohun 2004, 426-427), with Nestor's account praising both the horse and human halves of Cyllarus equally (Met. 12,393ff.) There is no indication of the violent demeanor that is exhibited by the other centaur guests, and none of the wild savagery that would traditionally accompany such an animal (Debrohun 2004, 430). Instead, Ovid provides the reader with quite a contradictory image of two centaurs in love.

It is also significant that we are offered a depiction of the female centaur, which is strikingly absent from many depictions of centaurs. ${ }^{9}$ This absence of female centaurs is noted by Philostratus in his Imagines, where he states that despite the belief that either the 'race of centaurs sprang from trees and rocks,' (Phil. Im. 3,3 ) or that they came into being simply from the male centaur, a more plausible explanation would be a belief in the existence of female centaurs. The female

\footnotetext{
${ }^{8}$ For a discussion of the place of the Centauromachy within the context of both Book 12 and the Metamorphoses as a whole, particularly its relationship to the Homeric epics, see Zumwalt 1977 and Musgrove 1998.

${ }^{9}$ Lucretius (Lucr. 5,922), as Debrohun notes, does not deign to give mention of female centaurs, as even male centaurs are unfathomable (Debrohun 2004, 445). This is not to say that the impression of a female centaur is unique to Ovid; as will be discussed, it is the presence of the female centaur in Lucian's Zeuxis and in the Metamorphoses that encourages a reading of Lucian's use of centaurs as manipulating the trope of the hybrid.
} 
centaur, as we shall also see in Lucian, is inherently distinct from the traditional portrayal of the male centaur. For Philostratus, the female is elegant in form when merged with the horse, and likened to the appearance of the Amazons (and if you were to remove the horse part, Naïads) (Phil. Im. 3,3). This is quite different from the non-human violence exhibited during the centauromachy. Similarly for Ovid, while the female centaur is described as being among the race of hybrids, (semiferos; Ov. Met. 12,406), it is her human qualities that are the focus. As Debrohun outlines, there is a likeness between the actions of the female centaur and the instructions offered women in Ovid's own Ars Amatoria, to the extent that her equine features are barely mentioned, and if they are, it is as evidence of feminine, human, preening (DeBrohun 2004, 435-438). ${ }^{10}$ The female centaur in particular, as she appears in Ovid and Philostratus, is herself a more humanised version of the traditionally savage centaur. As will be shown through Lucian's Zeuxis, such humanising can also occur in similar measure for the male counterpart.

This tension between the savage and the civilised centaur is particularly important for the following argument, as it is possible to view a similar tension between Lucian's two works. Chiron, the famously just and moral centaur, exemplifies the connection between civilised behaviour and paideia. As the teacher of Achilles, he stands in direct contrast to the philosophers of Lucian's Symposium. Unlike contemporary philosophers, the idealised, civilised centaur can embody an ideal of philosophical education.

Consequently, the hybrid animal becomes significant for understanding the role of philosophy in Lucian's works, for as will be shown, it is the philosophers who come to take on the traditional role of the non-human centaur. The philosophers in Lucian's Symposium are evaluated against the precedent set in Plato's Symposium, as the juxtaposition of the ideal philosopher against the corrupted sophist reveals Lucian's particular use of this familiar literary tradition to evoke hybridity of form and function. For Lucian, the sophists are savage and violent, while the centaur retains its humanity.

\section{Lucian's Zeuxis: Framing the Centaur}

Lucian's Zeuxis presents a humanised, even civilised centaur, like that which appeared more briefly in Ovid's Metamorphoses. Lucian's monologue consists of two parts, both addressing the notion of receiving praise that does not identify the

\footnotetext{
10 'And she was dainty, if such creatures could be, combing her hair, or mane, twining her locks with rosemary, or violets, or roses, or sometimes white lilies' (Ov. Met. 12,407-410; Humphries (tr.) 1955, 297). Emphasis added.
} 
real strengths of a work of art. The first part portrays the painter Zeuxis as scornful of his artwork being applauded for its novelty rather than its skillful composition, and it is this section that will be the focus for the following discussion, as the painting of Zeuxis depicts a family of centaurs. These centaurs, not unlike those depicted in the middle of Ovid's Centauromachy, are detached from their traditional nature. They are removed from the savage centauromachy, and instead are situated in an idyllic, bucolic setting.

In this painting of a family of centaurs, the female feeds her two young, while the male stoops over ( $\dot{\varepsilon} \pi \kappa v i \pi \tau \varepsilon$ ) the mother and her foals, dangling a lion cub above the children and playfully scaring them. Despite his laughter, states the narrator, the male centaur is entirely beast-like, savage, and wild. However the centaurs, as will be discussed, embody features of both the human and the horse equally, creating a hybrid pleasing to the eye. Despite the inherent savagery of the centaur, the depiction epitomises the successful hybrid creature.

von Möllendorff, in his discussion of the hybrid animal in Lucian's works, identifies the features of the successful hybrid. A combination, he states, of two $\kappa \alpha \lambda o$, does not guarantee a beautiful hybrid, but rather the successful Lucianic hybrid must offer:

The artful presentation of natural liveliness and movement, the avoidance of abrupt contrasts and exaggerated and undifferentiated uniformity, the creation of colourful variety and at the same time the skillful achievement of the effects of symmetry, well-balanced structure and disposition, an impression of serenity and placid buoyancy instead of distorted effects, but at the same time the attempt to join together that which is disparate ${ }^{11}$ (von Möllendorff 2006, 72).

The successful hybrid must appear to be natural, as indicated in Lucian's Prometheus. It should not be some kind of monstrosity like the half-black, half-white man (Prom. Es. 4), who represents the way in which a melding of two disparate things can achieve nothing of this 'well-balanced structure and disposition' (von Möllendorff 2006, 75). Curiously, in Lucian's Prometheus, it is in fact the centaurs that become the epitome of the disharmonious hybrid, as they are represented in paintings as drunks and murderers (Prom. Es. 5). This is, however, the precise opposite of our narrator's description of Zeuxis' piece, in three primary ways.

First, the centaurs of Zeuxis do, in fact, align with the Lucianic perception of a successful hybrid. The artist has displayed:

${ }^{11}$ Emphasis added. 
...precision of line, and accuracy in the blending of colours, well-suited application of the paint, correct use of shadow, good perspective, proportion, and symmetry (Zeux. 5).

Additionally, the female centaur is described as having the human and equine parts of her joined perfectly - there is no 'abrupt transition', nor is it obvious to the viewer that there has been a joining of two separate halves (Zeux. 6). Lucian's commentary upon Zeuxis' skill in composing the painting is, in and of itself, a unique aspect of his ekphrasis. As Pretzler notes, ekphrases throughout ancient literature tend to focus far more emphatically upon the content of a work of art, rather than the composition (Pretzler 2009, 160-161). This choice to focus upon the $\tau \dot{\varepsilon} \chi v \eta$ of the painting, she argues, accentuates that the artist has managed to make the unnatural natural (Pretzler 2009, 167), becoming representative of the true, uncorrupted hybrid animal. ${ }^{12}$

Secondly, there is nothing of the savagery that is exhibited in the Prometheus. Unlike Ovid, Lucian does not avoid the female centaur's equine features, but both the horse and the human aspects are treated in an equal and balanced manner. The human features act in a human way, while the equine half of her is treated as though a horse, with the two coexisting harmoniously. This is perhaps most evident when she is described as feeding her foals:

She holds one of her offspring aloft in her arms, giving it the breast in human fashion; the other the suckles in a horse-like manner (Zeux. 4).

Additionally, both parts are things of beauty; the equine part of her is $\kappa a \lambda \lambda i \sigma \tau \eta$, not unlike the horses of Thessaly, and her human half is likened to a very beautiful woman, despite having the ears of a satyr. ${ }^{13}$ The foals themselves are not entirely free from potential savagery; their childhood is described as wild and fearsome, but they are nevertheless quite harmless.

Finally, it should not be ignored that the wild nature of the male centaur is not wholly suppressed, as he is described as being 'completely frightening and abso-

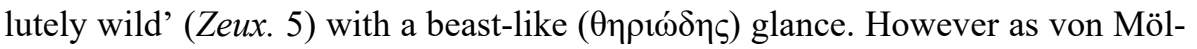
lendorff notes, the horse half of the centaur is quite literally hidden from view, as he is 'not completely visible, but only to a point halfway down his horse body' (Zeux. 4; von Möllendorff 2006, 77.). While he retains the inherent savagery of

12 This is true too, of Lucian's own use of the centaur as a metaphor for his own hybrid literary creation in his Prometheus (ní Mheallaigh 2014, 3-5).

${ }^{13}$ Here, we can recall Philostratus' description of the female centaur, which also identifies particular features that contribute to the appearance of the centaur (Phil. Im. 3,3). 
the centaur, this is not indicated through his equine features, but through his human form (Pretzler 2009, 167). Nevertheless, it is clear that he frightens his young with the lion cub in jest, as is indicated by his laughter at the introduction and the conclusion of his description (Zeux. 4; 5; von Möllendorff 2006, 77). This potentially wild creature is softened through his interaction with his family, ${ }^{14}$ and while the savagery is not entirely removed from the male centaur, he is nevertheless humanised.

There indeed exists a similarity between the depiction in Zeuxis and that found in the midst of Ovid's re-telling of the battle between the centaurs and the Lapiths. Not only is there a diminishing of the traditional centaur-like savagery, but there is in both instances a humanising element. The centaurs, for Ovid, fall in love just as the Lapith bride and bridegroom do, and in Zeuxis, there is the depiction of a close-knit, human-like family unit.

The centaurs of Lucian's Zeuxis and Ovid's Metamorphoses are of course not unique in being made civilised. Famously Chiron, as the teacher of Achilles, adopts the epithet 'most just of the centaurs' throughout the literary tradition (esp. Il. 11,832), and as Fantham notes, Ovid's Fasti humanises this civilised centaur in a similar manner to the depiction in the Metamorphoses: through an omission of any equine features (Fantham 2003, 116-117). Chiron, as a humanised centaur, is a figure who represents a learned hybrid and acts as a contrast to the traditional depiction of the centaur. Chiron is predominantly characterised by his morality and role as pedagogue (Gisley-Huwiler 1986, 237), yet he is also inherently a character with a dual literary function, having a savage and uncivilised appearance which belies his real nature. This is significant when juxtaposed with Lucian's depiction of both centaurs and philosophers, as the centaurs of Zeuxis may also be viewed as humanised. In direct contrast, the so-called philosophers are shown to adopt the characteristics of the uncivilised centaur, an inferior incarnation of the 'most just' Chiron.

${ }^{14}$ Lucretius proposes that parental love is a natural response, arguing from clear animal examples: the mother of a sacrificial calf presents symptoms of bereavement, and the nurturing of offspring is a natural phenomenon due to the requirement of milk for the young (Lucr. De Rerum Natura 2,349ff.) There has been some discussion in recent scholarship of the philosophical implications of attributing the capacity for parental love to animals. McConnell notes that Lucretius' position is curiously contradictory to Epicurus. McConnell argues that Lucretius' manipulation of Epicurean doctrine allows for humans and animals to be attributed parental love by nature, as it is in the context of civilised and domesticated existence (McConnell, 2016). If the civilised human experiences natural parental love, the attribution of parental love to a traditionally uncivilised hybrid arguably further humanises the figure of the centaur. For additional instances of parental love as natural to all animals, see Philostratus' VA. 2,14. 
The ekphrastic description of the family of centaurs stands in a stark contrast to the usual image of the violent, savage creature. By composing a work that in essence humanises the hybrid, Lucian portrays the means by which hybridity, when produced skillfully, can indeed become a thing of beauty. It is not unreasonable to interpret such a position as being in some ways self-reflexive, inciting a reconsideration of his assertions that his works are centaur-like in their mixing. ní Mheallaigh rightly notes that this dual depiction, in both Prometheus and Zeuxis, of centaurs and their hybridity enforces the admiration of the skill and novelty of its own hybrid genre (ní Mheallaigh 2014, 3). However for the following discussion, the focus is not on the means by which the hybrid is an exercise in reflexivity, but rather as a tool to critique the unsuccessful and corrupted hybrid. In considering Zeuxis to be a positive representation of hybridity, it is crucial to consider this in the context of more negative depictions of centaurs. Keeping the imagery of Ovid's Centauromachy in mind, the 'centaurs' of Lucian's Symposium can be contextualised in this framework.

\section{Symposium}

Lucian's Symposium, or the Lapiths, is composed as a reworking of his Cynic alter-ego Menippus' dialogue (Ath. 14,629F). While Menippus' work is now lost, Lucian's dialogue consists of a re-telling of a wedding feast celebrating the marriage of Cleanthis and Chaereas. Lycinus recalls the various guests at the dinner, namely 'philosophers and literary men' (Symp. 6), and the reader is introduced to representatives from various philosophical schools: a pair of Stoics (Zenothemis and Diphilus) a Peripatetic (Cleodemus), an Epicurean (Hermon), and a Platonist (Ion). ${ }^{15}$ As soon as the guests take their seats, the opposing philosophical schools begin to quarrel, bickering amongst themselves and talking behind each other's backs (Symp. 9-12). In the midst of the dinner, an additional philosopher appears, a Cynic, by the name of Alcidamas, who causes a stir among the guests, then reclines with a drink, 'just as Herakles in the cave of Pholus is represented by the painters' (Symp 14).

This mythic allusion, in addition to the dialogue's subtitle and setting, encourages readers to see these philosophers as centaur-like. The myth of Herakles and

${ }^{15}$ See too Lucian's Philopseudes: those present at the house of Eucrates are Cleodemus the Peripatetic, Deinomachus the Stoic and Ion, representing Plato, which suggests that the names hold some significance (Philops. 6). The dialogue also mimics the Symposium in a similar way to the Lapiths - instead of Alcibiades/Alcidamas, Philopseudes features Arignotus as the late arrival (Philops. 29; Männlein 2000, 248). 
Pholus, relates that the centaur was hosting the hero during his search for the Erymanthian boar. However, when the wine jar was opened at Herakles' request, a number of other centaurs rushed to Pholus' cave, so wild and savage that in Herakles' defence of himself, they fled to the cave of Chiron, resulting in Chiron's eventual death (Apoll. 2,83-87). Lycinus' likening of Alcidamas to Herakles in a cave of centaurs acts as a clear allusion to events that will follow: as the wine is passed throughout the wedding feast, the philosophers become enraged, not unlike the centaurs of myth.

It is necessary too, to explore the other namesake of the dialogue: Plato's Symposium. Lucian's Symposium structures itself in a similar manner to Plato's, by setting up the dialogue as a re-telling of the sympotic event. The attendees of Plato's Symposium are likewise 'philosophers and literary men' (Symp. 6), however unlike Lucian's fictional guests, Plato takes his characters from contemporary figures; those present at the dinner include Agathon, Aristophanes, Pausanius, Alcibiades and, of course, Socrates. Lucian also utilises the trope of a late arrival (Smith 2003, 280; Männlein 2000, 248), which appears in Plato's Symposium in the drunken arrival of Alcibiades (Pl. Smp. 212D). Yet for Lucian, this trope is expressed in three separate instances: not only is there Alcidamas' arrival (12), but there is also the arrival of the doctor, Dionicus, and the arrival of the Stoic Hetoemocles' slave. It is this last arrival that incites the commotion, with the slave giving a public address on behalf of his master. The address primarily attacks the host Aristenaetus for not inviting Hetoemocles, and praises the Stoic life over the opposing philosophical schools. Unsurprisingly, such a claim provokes a retort from Cleodemus (the Peripatetic), inciting the verbal argument that leads to the fighting. Enraged by the address, Cleodemus unmasks the famous Stoic founders, Chrysippus, Cleanthes and Zeno, as frauds, stating that they:

...make wretched little phrases and interrogations, philosophers in form, but most of them are like Hetoemocles (Symp. 30).

These Stoic philosophers are not, according to Cleodemus, real philosophers, and by striking the instigators of the philosophical doctrine, Cleodemus simultaneously ambushes other members of the school. Zenothemis defends his philosophical leaders, hurling insults back at the Peripatetic and the Epicurean until finally, boiling with rage, he overturns his cup of wine onto his opponents, inciting a brawl.

It is here that we receive a brief digression by the narrator, who comments upon his thoughts as he was watching the brawl take place. Lycinus expresses confusion as to the benefits of education, stating that these supposedly educated 
men are caught up in their own teachings, having regard for nothing else (Symp. 34). He is amazed that:

...though so many philosophers were present, there really was not one to be seen who was devoid of fault, but some acted disgracefully and some talked still more disgracefully (Symp. 34).

These philosophers, in both their words and actions, have become a source of disrepute for the race of philosophers more broadly. These learned men abuse each other, gorge themselves and brawl, while the so-called 'unlettered folk' laugh and observe. It is in this context that it is possible to view the particular hybridity of the dinner party that is facilitated by the elite and non-elite environment of Imperial Rome. ní Mheallaigh notes the way in which Lucianic hybridity frequently draws upon the distinctions between low and high cultures, allowing for a literary hybrid between the elite and non-elite (ní Mheallaigh 2014, 17-18). In the context of the Symposium, a similar hybridity is also expressed, however the distinction between the elite and the non-elite cultures may be identified through the overt mentions of wealth and reputation. The elitism of the symposium is shown even prior to retelling the violent feast, as the narrator Lycinus notes that the groom of the marriage is not only studying philosophy, but he is also descended from a very wealthy family (Symp. 5). While this does not strictly prevent the groom from being a student of philosophy, ${ }^{16}$ there is nevertheless an immediate tension between guests and the wedding party in terms of this elite and non-elite dichotomy. What's more, as the guests begin to seat themselves at the feast, Lycinus also relates that there exists a clear hierarchy between them, with each entering the symposium according to his reputation (Symp. 9; $\dot{\alpha} \xi \dot{\alpha} \alpha)$. Over the course of the party, their hybridity comes to show itself in more overt forms; while this is mainly represented through their devolution into centaur-like behaviour, prior to this, the educated elite, in the person of the grammarian, is shown to be combining the verses of various poets, arguably standing as an allusion to $\mathrm{Lu}-$ cian's own literary hybridity and its position within such an environment (Symp. 17). Lucian's intention here is to frame the remainder of the dialogue around this notion of hybridity, as the mixture of elite and non-elite cultures and genres allows to solidify the critique of the philosopher sophists. Our hybrid narrator, himself situated between the low and the high cultures of the Symposium (Symp. 9), serves to reflect upon the two types of hybridity that may present themselves in such an

${ }^{16}$ The complex relationship between this dialogue and others of Lucian with Cynicism lies outside the scope of this paper. 
environment. Where the narrator, Lycinus, remains separate from the 'philosophers and literary men', the philosopher-sophist hybrids, through their pretensions towards wisdom, are cast as corrupted hybrids, diminishing any of their claims to philosophical learning.

Lycinus, the narrator of Lucian's Symposium, expresses surprise that the sympotic environment no longer offers its participants philosophical wisdom, as it did in the Symposium of Plato. Lucian utilises the circumstances of Plato's Symposium to deliberately comment upon the absence of philosophical wisdom in contemporary symposia, by creating a stark contrast between the two sympotic texts so as to highlight the failure of philosophical education in Lucian's time.

There are a number of other striking differences between Lucian's and Plato's sympotic dialogues. First, the Symposium of Plato minimises the presence of both drinking and sympotic entertainment (Pl. Smp. 176a ff.), while drinking in the Lapiths remains prominent. Shortly after the arrival of Alcidamas, Lycinus relates that by then the kylix had been passed around the circle constantly (15). Alcid-

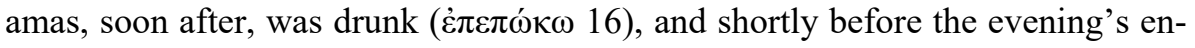
tertainment arrived, Lycinus observes that the rest of the guests were also drunk (17).

Secondly, where Plato's guests dismiss the dancing flute-girls to be entertained instead by simple conversation, the entertainment of Lucian's Symposium is not only present (in the form of a clown), but strikes blows with the drunken Cynic (19). Similarly, the act of eating during the symposium is brought to excess and greed in Lucian's version. Lycinus relates the range of dishes available to the guests (11), Alcidamas' rage is shown to be quelled by the sight of an enormous cake (16), and the second episode of brawling comes as a result of some guests receiving a smaller portion of dinner (43). These features of the symposium are taken by Lucian to the farthest extreme. König states that the 'transgressive potential of eating and drinking, as bodily practices, can undermine elite pretentions' (König 2012, 233-234), ${ }^{17}$ and such a transgression is quite deliberately implemented by Lucian as a means to denigrate the characters of the symposium. Lucian's overt depiction of this transgression sets up a contrast between the two symposia and evokes the inherent hybridity of the sympotic environment. There exists this tension between the act of philosophical discussion and the act of revelry, suggesting that the space in and of itself stands as a hybrid. This hybridity of

${ }^{17}$ Such a sentiment is similarly found in Bakhtin's discussion of the banquet, wherein he discusses the sympotic setting and its association with eating and drinking as a place where truth may be freely spoken, suggesting a transgressive element to the banquet environment. What's more, he states, 'the grotesque symposium does not have to respect hierarchical distinctions; it freely blends the profane and the sacred, the lower and the higher, the spiritual and the material' (Bakhtin 1968, 285-286). 
the symposium is reflected in Xenophanes' description of a symposium, wherein there is the explanation of how to correctly conducting oneself at the symposium, only to then describe the kind of drinking and festivities that should follow as the evening continues (Xen. Fr. 1). Nevertheless, there is also the suggestion that excess, in any form becomes counterintuitive to the overall virtue of the symposium, to the extent that even speaking of such topics such as the centauromachy should be avoided (Xen. Fr. 1) ${ }^{18}$ The hybridity of the symposium that is outlined in Xenophanes' text is echoed in Lucian's depiction, yet is naturally taken to the farthest extremes. This depiction of excess beyond what could be considered a successfully hybrid symposium presents precisely Lucian's concerns with contemporary philosophy, and those who practice it.

The supposed norm or ideal of the sympotic environment is reflected in Plutarch's Quaestiones Conviviales. It is argued by the character Crato that to remove philosophical conversation from the sympotic environment is both foolish and unheard of, to which Plutarch himself adds that it entirely depends on who those present happen to be. If, he states, the guests are fond of learning, then philosophical conversation is expected, however if the company is made up of those who appreciate bird song and music, it is likely to end in disagreement (Plu. Quaes. Conv. 613d-f). The appropriateness of the forum for philosophical discussion must be determined by the configuration of the guests: pretensions of sophistic discussion in the context of a drinking-party are entirely unsuitable (Plu. Quaes. Conv. 614e ff.). It is precisely this notion of a sham philosophical symposium that Lucian draws upon in his satirical dialogue. Rather than positioning the "philosopher-guests' in a sympotic environment that educates them and improves their lives through philosophical and learned discussion (König 2012, 30-59; Jaeger 1945, 213-262), Lucian's 'untrustworthy caricatures of real philosophers' (Männlein 2000, 248) undertake the activity more appropriate for those who entirely dismiss philosophy from the sympotic table. Rather than undertaking what may be understood as 'civilised' conversation, the guests of Lucian's Symposium not only eat and drink to excess, but find their entertainment in disputing the validity of their opposition's philosophical doctrines. These philosophers, as Männlein argues, become mere imitators of the philosophical founders whose doctrines they espouse (Männlein 2000,253), emulating neither a philosopher nor a rhetorician, but the hybrid sophist, wholly dedicated neither to philosophy nor to ignorance.

${ }^{18}$ For a more comprehensive discussion of this fragment of Xenophanes, see Marcovich 1978 and Bowra 1938. 


\section{Centaurs at the Symposium}

As Lucian's Symposium approaches the final conflict among the warring philosophers, the reader is exposed to the true nature of each philosophical school. The Cynic has not a single ounce of regard for his environment, the Stoics are portrayed as driven by greed, and as each doctrine finally chooses its 'side', the violence and savagery that is quintessential to Ovid's centauromachy is revealed. Lucian's Symposium depicts similar violence to that outlined above: eyes are gouged from their sockets, jaws are broken, women are screaming and crying as the battles rages on. The banquet room is now literally described as a space for two armies to meet ( $\mu \varepsilon \tau \alpha i$ í $\mu 10 v)$, and Lucian even employs an Iliadic quotation as a small bowl is thrown across the room, narrowly missing its target (Symp. 44). ${ }^{19}$ In the narrator's near-closing remarks, he states that:

...you would have said they were Lapiths and Centaurs, to see tables going over, blood flowing and cups flying (Symp. 45).

The philosophers, already proven to excess in their eating and drinking, are depicted as uncivilised in their sympotic behavior and utterly uneducated in philosophy, re-enacting as they do the famous battle of hybrid animals. The correct manner of conducting oneself during a symposium, as outlined through Plato and Plutarch, has fallen by the wayside, and it has become clear that the claims of contemporary philosophy to wisdom are false.

Through the depiction of contemporary philosophers as centaur-like, Lucian's interpretation of the sympotic environment manipulates the notion of philosophy as paideia through a recasting of contemporary philosophical conversation as failing to offer its participants education. Lucian's sympotic interpretation of the famous centauromachy exhibits a de-humanising, as the philosophers become like the traditional hybrid centaur, exhibiting their bestial nature over any human characteristics.

\section{Conclusion}

These two dialogues of Lucian, the Zeuxis and the Symposium, present the motif of the centaur in two distinctly separate contexts. In the first instance, the nature of the hybrid animal is considered, while in the second Lucian comments upon

${ }^{19}$ Agamemnon is battling the Trojan Iphidamas, when his spear misses his opponent (Il. 11,233). 
the failings of contemporary philosophy. The supposedly educated and wise philosophers are cast as savage, hybrid centaurs, while the hybrid animal itself comes to exhibit civilised behaviour. The philosopher as some kind of hybrid animal is not a notion restricted to this particular dialogue, nor to Lucian, but its development here contributes powerfully to Lucian's ongoing satirical polemic against philosophers. The philosophical hybrid, when contrasted with overtly humanised centaurs in the Zeuxis, offers a striking role reversal: the centaur approaches a human character, rather than a class of humans being bestialised by taking on the extremes of centaur behaviour. The savagery and the wildness that so defines the centaur breed is all but removed in Zeuxis, and instead the reader is left with the impression that the hybrid may not be the abhorrent and repulsive thing that permeates popular understanding. Rather, through the deftness of Zeuxis' skill, the hybrid animal is portrayed as a thing of (almost) human beauty.

These two dialogues, when viewed side-by-side, reflect a Lucianic concern with the nature of the contemporary philosopher. While the Zeuxis on its own stands as a more considered evaluation of Lucian's own works and their value as a hybrid genre, the work also acts as a consideration of the dichotomy between the elite and the popular. By recognising the disjunct between the perception of the artwork and the artist's intention, notions of perceived value can be understood as being emphasised in this dialogue. The suggestions that the hybrid has value on the basis of novelty offers a reflection upon the way in which elite and nonelite values are proliferated in society - and the way in which such values may be painted simultaneously. With this element of the Zeuxis in mind, it is possible to consider the motif of the centaur in this work as having a more forceful relationship with the centaurs of Lucian's Symposium. Here, the value of the philosopher has sunk so low that their elevated position is no longer justified, a clear reflection upon the notions of perceived value that is considered in the Zeuxis. Despite their supposed education, they act disgracefully. Additionally, where the philosopher in the Symposium is symbolically removed from humanity, the hybrid centaur in Zeuxis has its humanity emphasised. For Lucian, a successful hybrid 'attempt[s] to join together that which is disparate,' on the proviso that the balance is not disrupted. The philosopher-sophists, for their false professions of wisdom and education, have damaged this balance through their greed, overtaking the centaur as the epitome of the unsuccessful hybrid, while the 'uneducated' simply laugh and pass judgment on those whom they used to admire. ${ }^{20}$

\footnotetext{
${ }^{20}$ I would like to thank Graeme Miles for his support and invaluable assistance in producing this paper, and also the extremely constructive and insightful comments from those who reviewed it.
} 


\section{Bibliography}

Bakhtin, M and Iswolsky I (tr.) 1968. Rabelais and His World, Cambridge: M.I.T Press.

Billault, A. 1993 'Le Personnage de Philostrate dans la Vie d'Apollonios de Tyane: Autoportrait de l'auteur en biographie,' in: M-F. Baslez, P. Hoffmann and L. Pernot (eds.), L'invention de l'autobiographie d'Hesiode à Saint Augustin, Paris: Presses de l'École Normale Supérieure, 271-278.

Billault, A. 1993. "The Rhetoric of a "Divine Man": Apollonius of Tyana as Critic of Oratory and as Orator according to Philostratus', Philosophy \& Rhetoric 26, 227-235.

Bowra, C.M. 1938. 'Xenophanes, Fragment 1', Classical Philology 33:4, 353-367.

Bremmer, J. 2012. 'Greek Demons of the Wildnerness: The Case of the Centaurs', in: L. Feldt (ed.) Wilderness in Mythology and Religion: Approaching Religious Spatialities, Cosmologies, and Ideas of Wild Nature, Berlin: DeGruyter, 25-54.

Cohoon, J.W. (tr.) 1932. Loeb: Dio Chrysostom I: Discourses I-XI, Cambridge: Harvard University Press.

Debrohun, J.B. 2004. 'Centaurs in Love and War: Cyllarus and Hylonome in Ovid "Metamorphoses" 12.393-428', The American Journal of Philology 125, 393-428.

Fairbanks, A. (tr.) 1931. Loeb: Philostratus and Callistratus, Cambridge: Harvard University Press.

Fantham, E. 2003. 'Chiron: The Best of Teachers', in: A.F. Basson and W.J. Dominik (eds.) Literature, Art, History: Studies on Classical Antiquity and Tradition - In Honour of W.J. Henderson, Frankfurt: Peter Lang: 2003, 111-122.

Gisley-Huwiler, M. 1986. 'Cheiron', in: L. Kahil, Lexicon Iconographicum Mythologiae Classicae III: 1 (LIMC), Zürich-München: Artemis Verlag, 237-248.

Harmon, A.M. (tr.) 1913. Loeb: Lucian in Eight Volumes - I, Cambridge: Harvard University Press.

Humphries, R. (tr.) 1955. Ovid: Metamorphoses, Bloomington: Indiana University Press.

Jaeger, W. 1945. Paideia: the Ideals of Greek Culture, Oxford: Basil Blackwell.

Kapchan, D.A., Strong, P.T. 1999. 'Theorizing the Hybrid', The Journal of American Folklore $112,239-253$.

Kapchan, D.A. 1996. Gender on the Market, Moroccan Women and the Revoicing of Tradition, Philadelphia: University of Pennsylvania Press.

Kilburn, K. (tr.) 1959. Loeb: Lucian in Eight Volumes - VI, Cambridge: Harvard University Press.

König, J. 2012. Saints and Symposiasts: The Literature of Food and the Symposium in GrecoRoman and Early Christian Culture, Cambridge: Cambridge University Press.

König, J. 2009. Greek Literature in the Roman Empire, London: Bristol Classical Press.

Männlein, I. 2000. 'What Can Go Wrong at a Dinner-Party: The Unmasking of False Philosophers in Lucian's Symposium or the Lapiths', in: K. Pollmann, Double Standards in the Ancient and Medieval World, Göttingen: Duehrkohp und Radicke, 247-262.

Marcovich, 1978. 'Xenophanes on Drinking-Parties and Olympic Games', Illinois Classical Studies 3, 1-26.

McConnell, S. 2016. 'Lucretius on Parental Love', paper presented to Australasian Society for Classical Studies $37^{\text {th }}$ Annual Meeting, Melbourne University, $4^{\text {th }}$ February 2016.

ní Mheallaigh, K. 2014. Reading Fiction with Lucian: Fakes, Freaks and Hyperreality, Cambridge: Cambridge University Press.

Moles, J. 1983. 'The Date and Purpose of the Fourth Kingship Oration of Dio Chrysostom', Classical Antiquity 2, 251-278. 
von Möllendorff, P. 2006. 'Camels, Celts and Centaurs: Lucian's Aesthetic Concept - The Charis of the Hybrid', in: R.R. Nauta (ed.), Desultoria Scientia: Genre in Apuleius' Metamorphoses and Related Texts, Leuven - Paris - Dudley, MA.: Peeters, 63-86.

Musgrove, M. W. 1998. 'Nestor's Centauromachy and the Deceptive Voice of Poetic Memory (Ovid Me. 12.182-535), Classical Philology 93, 223-231.

Pretzler, M. 2009. 'Form Over Substance? Deconstructing Ecphrasis in Lucian's Zeuxis and Eikones', in A. Barkley (ed.), A Lucian for Our Times, Newcastle Upon Tyne: Cambridge Scholars Publishing, 157-172.

Smith, D.E. 2003. From Symposium to Eucharist: The Banquet in the Early Christian World, Minneapolis: Fortress Press.

Stross, B. 1999. 'The Hybrid Metaphor', The Journal of American Folklore 112, 254-267.

Whitmarsh, T. 2005. The Second Sophistic, Oxford: Oxford University Press.

Zumwalt, N. 1977. "'Fama Subversa": Theme and Structure in Ovid "Metamorphoses" 12', California Studies in Classical Antiquity 10, 209-222. 